\title{
Analysis of the Interaction between Casing and Completion Packer Slip in HPHT Wells
}

\author{
Xin Sun ${ }^{1, a}$; Yihua Dou ${ }^{2, a}$; Heng Song ${ }^{1, a}$; Xing Wang ${ }^{3, a}$; Yinping Cao ${ }^{2, a}$ \\ ${ }^{1}$ PetroChina Xinjiang Oilfield Company, Kelamay, Xinjiang, China, 834000 \\ ${ }^{2}$ Xi'an Shiyou University, Xi'an, China, 710065 \\ ${ }^{3}$ CNPC Chuanqing Drilling Engineering Co.,Ltd, Xi'an, China, 710021 \\ acaoyinping029@163.com
}

Keywords: high temperature high pressure (HPHT); packer; slip; casing; interaction

\begin{abstract}
Completion packer slips have the effect of supporting the packer by anchoring and locking packer rubber in high temperature and high pressure (HPHT) wells, which are an important component for ensuring the reliability of the packer. There are interactions when slips and casing contact with each other, which would generate interactive forces, and the supporting forces of slips mainly relay on the interactions between slips and casing. In this paper, the interactions between slips and casing have been studied by theory and finite element method based on ANSYS. The depth of slip bit into casing and the rules of interaction between slips and casing were found from above research. It was found that the bite depth of HPHT completion packers was generally about $0.7 \mathrm{~mm}$. And, the load acted on the slip elements tip will increase with the increase of the axial load acted on the cone, while decrease with the slip elements number.
\end{abstract}

\section{Introduction}

The slips of the packer are important components ensuring the reliability of the packers ${ }^{[1]}$. After the packer down to the desired depth, the setting force is transferred to the slip cone through the packer cone under the action of axial loads. Due to the cone angle is generally small, it will produce a large radial load, under which slips bit into the casing wall for a certain depth, so the clips card on the casing wall, which have the effect of supporting packer. The formula of contact force between slips and casing would be obtained according to the mechanical analysis of the slips, and the finite element model of the slip system composed of cone, slips and casing was established in this paper. The depth of the slip bit into the casing and the law of interaction between slips and casing would be obtained through the analysis.

\section{Analysis of contact force between slips and casing in HPHT wells}

The completion packer in HPHT wells is slip-type packer. When the axial force acting on the completion is too large, or the parameters of the slips are unreasonable, the slips or casing may be damaged. Therefore, it is quite necessary to analysis the contact force between completion packer slips and casing in HPHT wells.

As shown in Fig. 1, when the packer was set and the slip was anchored, the slip had been fractured. With the assumption of integrated slip being divided into the same pieces of the symmetry, force equilibrium equations of each slip can be established ${ }^{[2]}$ :

$$
\left\{\begin{array}{l}
Q_{r}=Q_{R}(\cos \alpha-\operatorname{tg} \phi \sin \alpha) \\
Q_{z}=Q_{R}(\sin \alpha+\operatorname{tg} \phi \cos \alpha)
\end{array} .\right.
$$


From the Eq. 1 above, we can get:

$$
Q_{r}=\frac{Q_{Z}}{\operatorname{tg}(\alpha+\phi)}=\frac{W_{1}}{n t g(\alpha+\phi)} .
$$

Where, $Q_{z}$ is the axial load acting on each slip, $Q_{r}$ is the radial load at the contact point in each piece of slips and casing wall, $Q_{R}$ is the load acting on each slip, $W_{1}$ is the total axial load acting on the slips of the packer, $\phi$ is the friction angle, $\alpha$ is the inclined angle at the top of slip, and $n$ is the number of the slips.

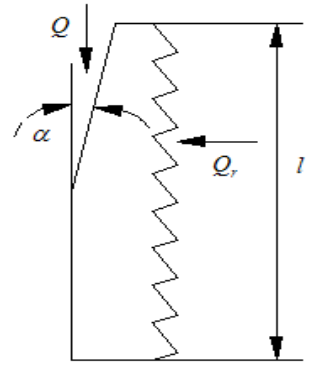

Fig. 1 Schematic diagram of slip exerted by the axial force

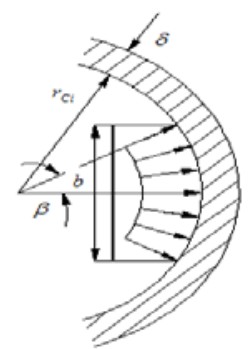

Fig. 2 Radial distribution force of the slip

As shown in Fig. 2, with the assumption of $Q_{r}$ being uniformly distributed along the radial direction on the inner wall of the casing, the relationship of uniformly distributed loads $q, Q_{r}$ and $W_{1}$ on the contact region between slip and casing can be obtained.

$$
\begin{aligned}
& Q_{r}=\int_{-\beta}^{\beta} q l \alpha \cos \theta d \theta=2 q l \alpha \sin \beta . \\
& q=\frac{Q_{r}}{2 l \alpha \sin \beta}=\frac{W_{1}}{2 n l \alpha t g(\alpha+\phi) \sin \beta} .
\end{aligned}
$$

Where, $r_{C i}$ is the inner radius of casing, $\beta$ is the half-angle of slips at the outer surface, $l$ is the axial length of slips at the outer surface, $q$ is the uniformly distributed load along the radial direction on the contact region between slips and casing.

\section{Analysis of the depth slips biting into casing in HPHT wells}

Because the casing is thin-wall tube, bite mark will form on the interface of casing when the slip bites into casing, and the casing may be damaged if the biting depth is too large. The shear force of the slip is related to the biting depth. The stress concentration appears because of the contact of slip element and casing, so it is necessary to analysis the depth of slip biting into casing with finite element method based on ANSYS.

(1) Elements in finite element model

Solid182 20 node element was chosen when analysis the contact process of slip and casing, and the surface to surface contact element of Targe169 and Con-ta174 on contact couple was chosen in ANSYS.

(2) Materials of casing, slip and cone

THT permanent packer has an integral slip for each side. This slip reliability of fit mode has been confirmed by the over cable setting permanent packer. Generally, this slip made by $125 \mathrm{MY}$ materials ${ }^{[5]}$, which are low carbon steels, and easy to grind and milling, and the elements which treatment by carburizing can ensure bite high strength casing. Material of casing is P110, and the material data of slip, cone and casing are shown in Table 1. 
Table 1 Material parameters of slip system

\begin{tabular}{|c|c|c|c|}
\hline & Elastic Modulus $E(\mathrm{MPa})$ & Poisson ratio $\mu$ & Yield limit $\sigma_{s}(\mathrm{MPa})$ \\
\hline Slip & $2.3 \mathrm{e} 5$ & 0.26 & 950 \\
\hline Cone & $2.3 \mathrm{e} 5$ & 0.26 & 900 \\
\hline Casing & $2.0 \mathrm{e} 5$ & 0.26 & 758 \\
\hline
\end{tabular}

(3) The Constraint conditions

The inside of the packer cone is limited by packer body, which can move only along the axial direction, while the radial movement is constrained. The bottom of the Packer slip is limited by packer body, which can move only along the radial movement, while the axial movement is constrained. The outside of the casing at packer is constrained by the cement and the formation, which can move only along the axial direction. The bottom of the casing can move only along the radial direction. Thus, the outside of the casing is constrained by the radial direction, and the bottom of the casing is constrained by the axial direction.

The radial displacements of the slip system while the slip biting casing were shown in Fig. 3. The axial displacement of each top of bite, i.e. depth of slip elements bite with casing, can be obtained by ANSYS analysis.
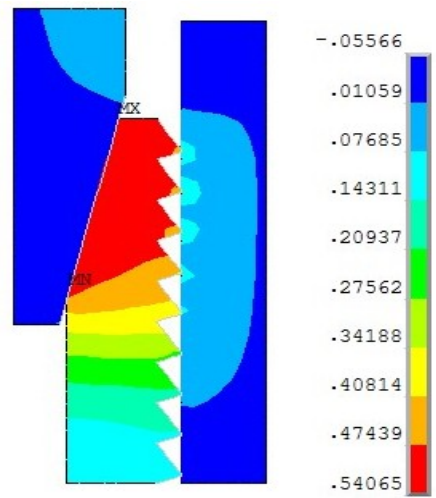

(a) $40 \mathrm{MPa}$

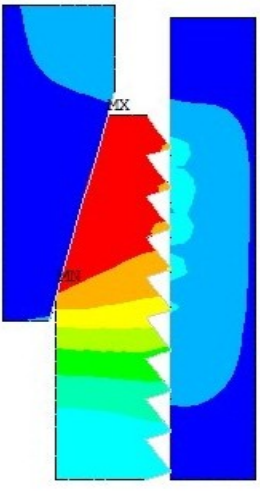

(b) $50 \mathrm{MPa}$

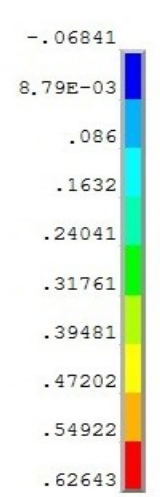

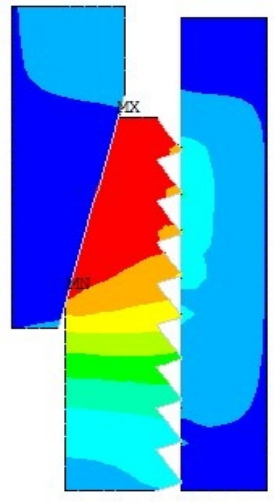

(c) $60 \mathrm{MPa}$

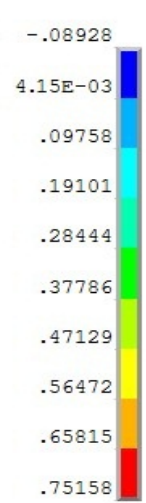

.75158

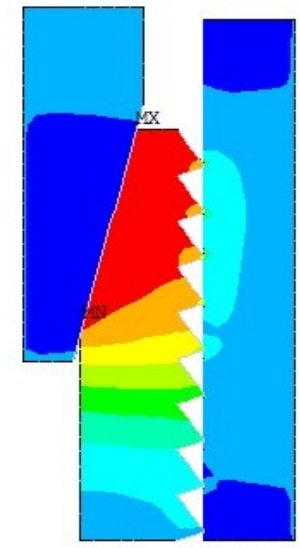

(d) $80 \mathrm{MPa}$

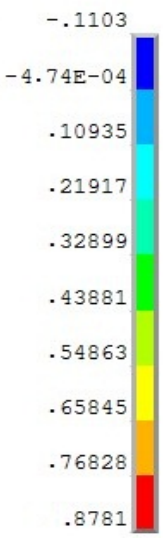

8781

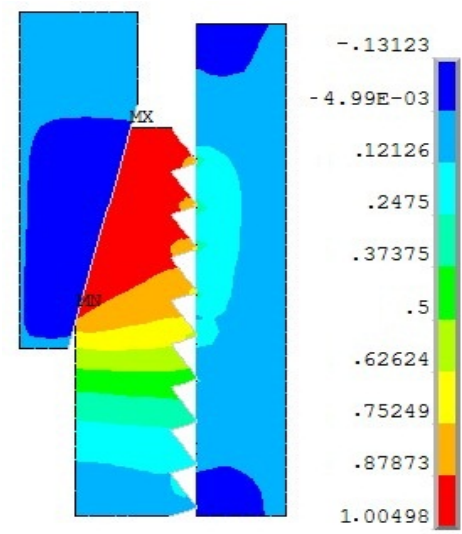

(e) $100 \mathrm{MPa}$

Fig. 3 Radial displacements of the slip system when axial load are 40, 50, 60, 80 and 100MPa

The curves of the slip biting depth change with loads were plotted in Fig. 4. It can be seen from Fig. 4 that biting depth in the same slip elements increases with the increase of load in HPHT wells, while, with the increase of the slip element numbers, biting depth gradually decreased. Generally, the loads applied on the cone by THT packers are 50 to 70MPa, so the bite depth of HPHT completion packers are about $0.7 \mathrm{~mm}$. 


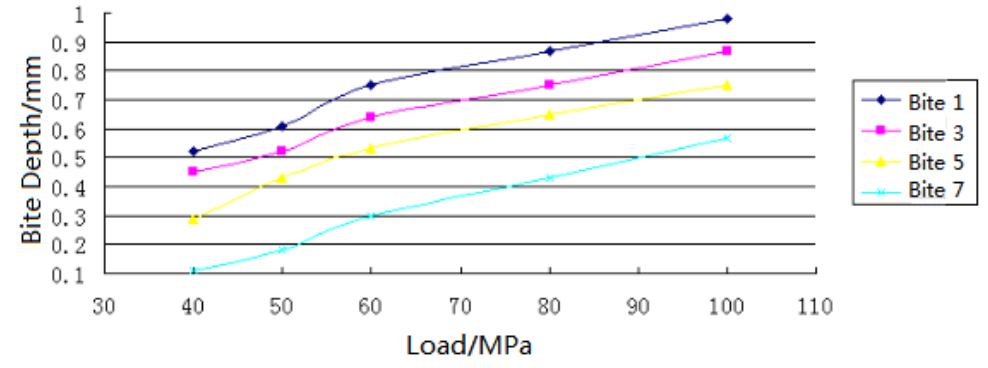

Fig. 4 The curve of slip bite depth varied with loads

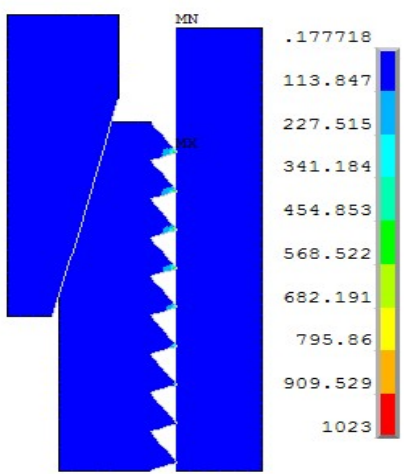

Fig. 5 Von Mises stress of the slip system when 50MPa load were applied

\section{Analysis of Von Mises Stress on Completion Packer Slip Elements}

Loads are applied on the top of the cone, which make the slips and casing contacted. The sealing pressure between packer rubber and casing inside can't ensure if the minimum sitting force didn't reach the minimum sitting force ${ }^{[6]}$, and the working pressure drawdown rating of packer can't ensure. Generally, the THT packer minimum sitting force is 50MPa, the maximum sitting force, which is the maximum pressure drawdown which packer slip can absorb is 110MPa, so the radial displacements and Von Mises stress of the slip system when axial loads as $50 \mathrm{MPa}$ was analyzed.

When the applied load is 50MPa, Von Mises stresses of the slip system were showed in Fig. 5. Sequencing the slip bites from the top to the bottom with bite 1 to bite 9, stresses of each slip elements when 40MPa load applied were showed in Fig. 6. We can see that the stress was maximum on the bite 1 , stress on bite 3 is about $70 \%$ of the bite 1 , stress on bite 5 is about $10 \%$ of the bite 1 , and stress on bite 7 is about $5 \%$ of the bite 1 , when the pressure on the top of cone was a constant. And, the forces on each slip bites were uniform and decreased nonlinearly.

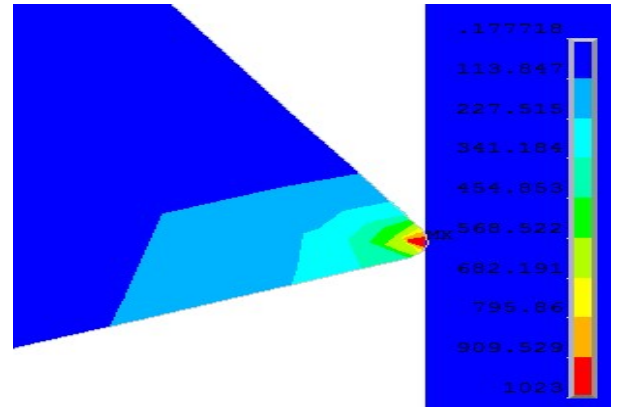

(a) Stress of bite 1

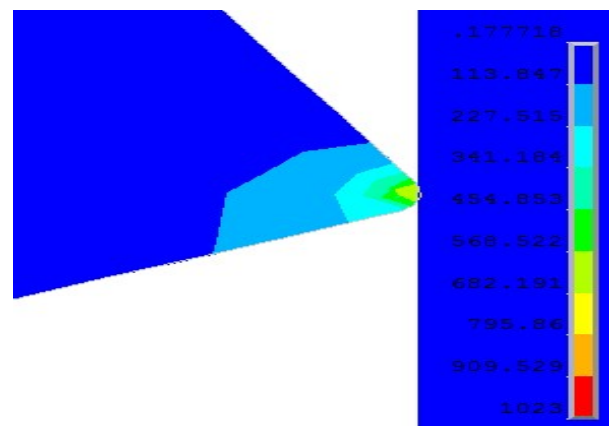

(c) Stress of bite 5

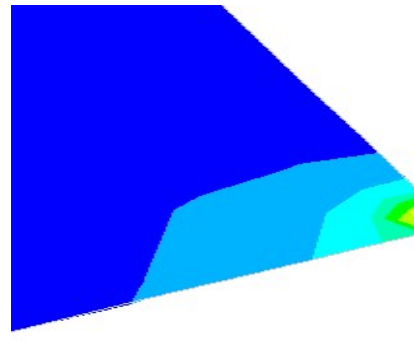

(b) Stress of bite 3

(d) Stress of bite 7

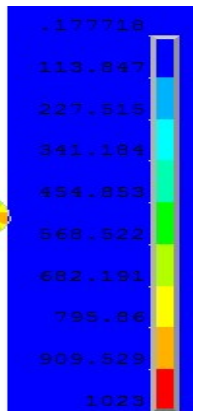

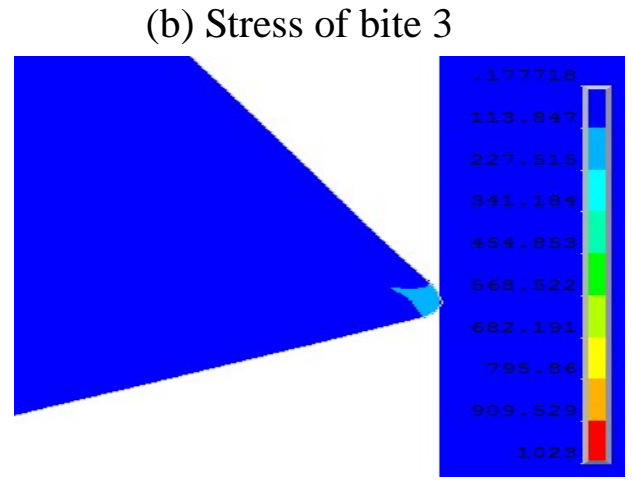

Fig. 6 Stresses of each slip elements when 50MPa load were applied

We can see that there is serious stress concentration at slip elements tip when slips and casing contacted each other, which was most evident at the first slip element. The load acted on the slip 
elements tip will increase with the increase of the axial load acted on the cone, while decrease with the slip elements number.

\section{Conclusions}

The interactions between slips and casing have been studied by theory and finite element method based on ANSYS in this paper, some conclusions could be drawn from the research.

(1) Bite depth in the same slip elements would increase with the increase of load in HPHT wells, while decease with the increase of the slip element numbers. The bite depth of HPHT completion packers was generally about $0.7 \mathrm{~mm}$.

(2) The stress in each slip elements will decrease with increase of the number. And, the slip bite depth as well as slip elements stress will increase with the increase of applied load.

\section{Acknowledgments}

This paper is supported by the project of the study of key technology on well testing and reservoir reconstructing from the key research projects of CNPC (No. 2012E-34-14).

\section{References}

[1] Wu Kaisong, Xie Bin, Yang Xinke. 3-D FEA of contact for slip system of packer systems. Oil Field Equipment. Vol. 34 No. 6(2005), p. 47-49.(in Chinese)

[2] Zhao Yuangang. Stress analysis and theory calculate of slip packer. Oil Drilling \& Production Technology. Vol. 10 No. 2(1983), p. 69-71.(in Chinese)

[3] Liu Tianliang, Xie Hongde, Wang Qian, et al. Simulated test research on casing failure caused by anchor packer. Oil Field Equipment. Vol. 30 No. 2(2001), p. 49-51.(in Chinese)

[4] Wang Lan, Zhang Lixun, Lu Haijun, et al. Simulate system of mode of packer operation. Applied Science and Technology. Vol. 27 No. 2(2000), p. 12-13. (in Chinese)

[5] Kan Shuhua. Analysis of the slip of a packer using the finite element method. Oil Field Equipment. Vol. 34 No. 1(2005), p. 62-64.(in Chinese)

[6] Wang Di, He Shiping, Zhang Xi. A Study on Contact Stress of Packer Slip. Journal of Experimental Mechanics. Vol. 21 No. 3(2006), p. 351-356.(in Chinese) 